CANADIAN JOURNAL OF

\title{
Disability Studies
}

Canadian Journal of Disability Studies

Published by the Canadian Disability Studies Association

Association Canadienne des Études sur le handicap

Hosted by The University of Waterloo

www.cjds.uwaterloo 


\title{
Semiotic Stalemate: Resisting Restraint and Seclusion through Guattari's Micropolitics of Desire
}

\author{
Robin Roscigno \\ Ph.D. Candidate \\ Department of Educational Theory, Policy, and Administration \\ Rutgers Graduate School of Education \\ robin.f.roscigno@gmail.com
}

\begin{abstract}
This article explores the semiotic relationships between Applied Behavior Analysis research, special education practice and restraint and seclusion policy by tracing the evolution of the concept of "self-restraint," — a term from Behavior Analytic literature for a variety of "behaviors" in which a person restricts their own movement. I trace how "self-restraint" emerges as a new class of behaviors eligible for intervention, and how this marks certain bodies for restrictive practices such as restraint, seclusion and the use of aversives. I explore how rhetorical moves shape the educational landscape of disabled students and expose mechanisms of control that are shaped by scholarship. By using "self-restraint" as an example, I respond to the taxonomies of deficit disseminated through Applied Behavioral Analysis in schooling for neurodivergent students and make critical links between special education practice and Disability Studies in Education.
\end{abstract}

\section{Keywords}

Autism, Restraint, Seclusion, ABA, Special Education, Semiotics 


\section{Introduction}

On November 28 $8^{\text {th }}$, 2018, 13-year-old Max Benson suffocated to death while being held in a "prone restraint" in the private school he attended, Guiding Hands School in El Dorado Hills, California. At the time of his death, Max had been held in the restraint for over an hour, prompting public outcry (Bonvillian, 2018; Luca, 2019; Morrar \& Reese, 2018). What are now well-worn tropes of the dangerous autistic man/child immediately characterized the reporting on Max's death. The reporting on Max's death prompted two treatments in the media. The first was to characterize Max as violent, large in stature, and out of control-his teachers also tragically victim to Autism (Escalante, 2018). News outlets reported false information about Max's stature, the nature of his behavior, and the frequency of his restraint in his school. All of these details point to the necessity and deservedness of his restraint and paint his death as a tragic cost of educating autistic students. The second media treatment characterized Max's death as an anomaly-highlighting the ways This Bad School violated otherwise safe and protective restraint guidelines (Luca, 2019). The discursive regimes that shape and enable restraint are the subject of interrogation in this paper. How did restraint enter special education practice? How is it sustained, and what semiotic processes underpin the formation of the terms of restraint? Who can be restrained, and for what? My goals here are to describe what I am terming a semiotic stalemate between the modes of control (restraint and seclusion) and the modes of resistance to date (better laws, training and oversight). Rights-based interventions into restraint and seclusion have done little to curb their use, as the political alliance of the law, school practice and behaviorist scholarship continuously evolve and redefine seemingly stable terms. My purposes here are to theorize how semiotic formations determine how we engage in activism around 
restraint and seclusion, and why the current strategies are inadequate to contend with a "Statepower machine" that depends on a totalitarian relationship to the signifier.

I begin by tracing a history of restraint as an "evidence-based" treatment within the episteme of behaviorist psychology. I argue that physical restraint is not an anomaly, rather a type of "normative violence" that has been ontologically sanctioned through a production of an evidence base for its use and the manufacturing of a need for its application. This is both a material and semiotic process through which a variety of bodily assemblages are imbued with a deviance that there is a readily available field to correct. I utilize Felix Guattari's concept of institutional semiotics (Guattari, 1984) to analyze semiotic formations within behaviorist scholarship and institutions like schools and therapy spaces. I am interested in how help, care, necessity, therapy, and treatment are deterritorialized and reterritorialized through signification processes, and consequently how human-rights based interventions fail to account for the layers of a-semiotic encodings and semiotically formed substances found within the behaviorist scholarship, educational practice and policy and the material resistances contained within.

Particularly, I will trace a concept from the behaviorist literature-self-restraint-to make clearer the way the political and social order molds the form/content relationship, and how this is of political utility to institutions. By form/content relationship I am referring to Saussure's understanding of signifier/signified (Saussure, 1966, p. 117). I look at policy to determine common legal justifications for the use of physical restraint-which often fall into discourses of "harm to others or oneself". My purposes here are to understand the discursive mechanisms at work that justify the use of restraint and seclusion in public schools. I argue that special education legislation, and the legislation that governs the use of restraint and seclusion in schools has an epistemological relationship with the field of Applied Behavioral Analysis, often times 
Roscigno, Semiotic Stalemate

CJDS 9.5 (December 2020)

adopting definitions, vocabulary and techniques from existing ABA literature. I plot how there has been a recent influx of Board-Certified Behavior Analysts into special education classrooms and programs, as many school districts open ABA classrooms, like the one Max Benson was educated in. I posit that many decisions regarding the material conditions of children are made based on the evidence-base of behavior analytic literature, and that the training of many special educators is predominantly based in behaviorism and how Applied Behavioral Analysis's operational definition of "self-restraint" serves to widen the definition of "harm to oneself or another" by creating a semiotic category that subsumes a wide variety of non-aggressive or physically dangerous activities. To conclude, I will return to Guattari to conceptualize what a "micro-politics" of desire affords the restrained child and locate desire and lines of flight within the episteme of behaviorist scholarship (Guattari, 1984).

\section{Behaviorism in Schools}

Behaviorism, or the study and shaping of the behavior through operant conditioning, was codified into a field in 1958, through the publication of the first dedicated journal to the experimental analysis of behavior, The Journal of the Experimental Analysis of Behavior. Through this publication and subsequently, the Journal of Applied Behavioral Analysis in 1968, behaviorism was almost immediately marketed to schools, promising to help improve discipline, decrease negative behaviors and improve classroom management. For example, the flagship issue of the Journal for the Experimental Analysis of Behavior (a collaborative effort between B.H. Skinner, Fred Keller, Sidney Bijou, among others) contains experiments conducted in the University preschool where Sidney Bijou was faculty and explored how often children would have to be reinforced to continue a task (Bijou, 1958). The first advertisement specifically 
Roscigno, Semiotic Stalemate

CJDS 9.5 (December 2020)

targeting educators was published in the second year of the journal (Foringer Co., 1959, n.p.).

The advertisement was published by Foringer \& Co. and advertised the production of teaching machines (machines were manufactured by such companies for use in behavioral experimentation) for "classroom application, program development and educational research"(Foringer Co., 1959, n.p.). In 1959, the Inaugural conference of the Conference of the Experimental Analysis of Behavior included an abstract for a paper titled "Multiple Scheduling in Children" which detailed an experiment conducted in a preschool using small tokens to demonstrate how children could be controlled through multiple schedules of reinforcement (“Abstracts of the Conference on the Experimental Analysis of Behavior," 1959). The Journal of the Experimental Analysis of Behavior was published by the Society for the Experimental Analysis of Behavior. By 1968, the Society released a second publication, the Journal of Applied Behavioral Analysis (JABA), which is presently the preeminent journal publishing ABA literature. In the first issue of JABA, the connection and application of applied behaviorism is well-established. Of the eleven articles included, seven are explicitly about the control of children (Hall et al., 1968; Hart et al., 1968; Keller, 1968; Thomas et al., 1968; Zeilberger, et al., 1968). This inaugural issue also contains what is the first of many articles specifically dealing with the deviance of autistic children. In "The Effects and Side Effects of Punishing the Autistic Behaviors of a Deviant Child," Todd R. Risely describes using electroshock to eliminate the “autistic rocking” of a six year old girl in his laboratory (Risley, 1968). From the onset, behaviorism had a reciprocal relationship with both schools and mental institutions. Many early behaviorists, like Ivar Lovaas and Sidney Bijou, ran centers within their universities that also functioned as schools, prior to compulsory schooling for students with disabilities (Bijou et al., 2009; Özerk et al., 2016). Such schools also became both an object of study, a repository of 
testing subjects, laboratory and consumer of behaviorism in the form of trainings, consultations, etc. with behaviorists. The rise of behaviorism in schools more broadly, particularly in schooling for the disabled, as I have shown, was not accidental. A concerted effort was made by the burgeoning field of Applied Behavior Analysis to both research and market their technologies of social control to public schooling, mental institutions and the clinic from the onset.

Over time, this relationship has become further entrenched. The formation of the Behavior Analyst Certification Board in 1998 established professional credentialing requirements outside of a scientific training in behavioral psychology, and helped to establish a further professionalization of the field (Behavior Analyst Certification Board, n.d.). Furthermore, the creation of a stand-alone certification enabled practitioners of ABA to bypass certification as a licensed psychologist, and to obtain certification through completion of a course sequence and an exam. This was largely to meet a demand for ABA practitioners, as the amount of diagnosed autistic children increased, and a national "crisis" of autism reached public consciousness (Deochand \& Fuqua, 2016). This corresponded with the creation of Autism Speaks in 2005, Talk About Curing Autism in 2000, and the Autism Research Institute's Defeat Autism Now (DAN) Protocol in 1995. Since the establishment of the BACB, the amount of Board Certified Behavior Analysts has increased from 28 to 32,008 in 2018 (Burning Glass Technologies, 2015). The BACB certified 3,437 BCBAs in 2018, with $67.65 \%$ working in Autism services and $12.24 \%$ working in Education (Burning Glass Technologies, 2015). A labor market survey conducted by Burning Glass Technologies, a software company that organizes and reports survey data related to the labor market, reported that of the jobs listed for BCBAs, $83 \%$ were related to Health Care, Education or Social Services, and 53\% explicitly referred to Autism in the job posting (Burning Glass Technologies, 2015). Teacher preparation programs often offer dual certification programs 
Roscigno, Semiotic Stalemate

CJDS 9.5 (December 2020)

in Special Education and Applied Behavior Analysis or offer stand-alone certification programs that meet the BACB course sequence requirements (Shook, 2005; Shook \& Favell, 2008; Shook \& Neisworth, 2005). ABA, at this juncture, is inextricably linked to Autism, as both instructional method of choice, most recommended therapy, and in many cases the only therapy covered by insurance (Maglione et al., 2017). The remainder of the paper will explore how school practice and policies related to the education of children with disabilities, in this case restraint and seclusion legislation, have a symbiotic relationship with the field of Applied Behavioral Analysis. Understanding the literature published within the field of ABA unlocks some of the assumptions of the research base that is most influential to special education practice. For example, the Code of Federal Regulation 34 CFR $\$ 300.530(f)$ specifies that when a child is removed from a placement for disciplinary reasons, they must "Receive, as appropriate, a functional behavioral assessment, and behavioral intervention services and modifications, that are designed to address the behavior violation so that it does not recur" (Individuals with Disabilities Education Act [IDEA], 2004). Defining behaviors by function is an explicitly behaviorist framing, developed by Brian Iwata et al. in 1982. This example illustrates how present-day special education classrooms are influenced and shaped by behaviorism, and how terms specifically coined in the Journal of Applied Behavioral Analysis travel and become entrenched in policy and practice.

\section{Restraint and Seclusion}

One such term and corresponding practice that has traveled from Behaviorism is the use of restraint as a teaching "procedure" as opposed to a crisis management protocol. Prior to the 
Roscigno, Semiotic Stalemate

CJDS 9.5 (December 2020)

development of operant conditioning, the function of restraint and/or seclusion was primarily safety. However, early-on, behaviorists began experimenting with restraint and seclusion as variables to be utilized within operant conditioning, by making restraint and or seclusion, or the release from restraint, conditional on desired behaviors. Behaviorist scholarship has advanced the use of restraint and seclusion as procedures for behavior management and instruction and established a research base for its use in teaching protocols. Several early examples of this application are published in JABA. In "Modification of severe disruptive and aggressive behavior using brief timeout and reinforcement procedures, two "retarded patients" in a mental hospital were placed in a "time out" for a duration spanning 10 minutes to 2 hours in order to decrease negative behaviors such as aggression and "loud vocal behavior" (Bostow \& Bailey, 1969). In this study, one participant -Ruth, a wheel chair user - was taken out of her chair and placed on the floor every time she made a loud vocalization and picked up from the floor only when she had been quiet for 15 seconds. This is one of the first articles published in JABA that explicitly calls for the seclusion or restraint of a person as a strategy for behavior modification. In another article published in JABA, "Training profoundly retarded children to stop crawling," researchers experimentally tested the use of restraint as a teaching procedure $\left(\mathrm{O}^{\prime}\right.$ Brien et al., 1972). Four children, ages 5-7, who were not yet walking, were restrained physically when they crawled for 15 seconds before being placed on their feet to walk and praised for walking. The idea that people - children - could be taught through contingent restraint and seclusion is explicitly formulated within the episteme of behaviorism.

Given the meteoric rise of behaviorism in schools, and the conduit between them, it is not surprising that restraint and seclusion are practiced in schools as instructional "strategies" as opposed to emergency management techniques. Several governmental watchdog organizations 
Roscigno, Semiotic Stalemate

CJDS 9.5 (December 2020)

have compiled testimony on restraint and seclusion $(R \& S)$ in schools including the

Governmental Accountability Office (Kutz, 2009) and the Senate (Harkin, 2014). In 2010, Rep.

George Miller introduced the Safety for Every Student Act, which would place limitation on the use of physical and mechanical restraint for public and private school students and outlawed seclusion (Keeping All Students Safe Act, 2010). The bill did not reach the floor. National news outlets have covered the topic as well. Several states have recently passed legislation on R\&S including New Jersey and Texas (N.J. Gen. Stat. §1163 1-5; Tx. Ed. Cd § 37.002). Public discourse has centered on the legality of the specific types of restraints, restraint trainings, staff oversight, interactions with the IEP process and mandated reporting.

This has led to a conflict that is as much epistemological as it is about practice. The process of limiting restraint ultimately rests on how one conceives of rights. What seems selfevident in this discourse, is that the invocation of rights would serve to limit restraint. However, behaviorist literature frames rights in a remarkably different way: through the rights of the individual to receive "evidence-based treatment." For example, a joint statement issued by the Association for Behavior Analysis International titled "The Association for Behavior Analysis International Position Statement on Restraint and Seclusion," stresses the evidence base and efficacy of restraint and seclusion in their defense of its continued use. They state,

A regulation that prohibits treatment that includes the necessary use of restraint violates individuals' rights to effective treatment. The irresponsible use of certain procedures by unqualified or incompetent people should not result in policies that limit the rights of those duly qualified and responsible for an individual through the process of making informed choices (Vollmer et al., 2011). 
This statement, issued in 2011, recapitulates the initial arguments of the early behavioristsrestraint and seclusion are necessary teaching tools and to limit them is actually an infringement on the rights of the individual. While activists against the use of $\mathrm{R} \& \mathrm{~S}$ claim human rights, so do the proponents of R\&S. Naming this tension of signification between the law, practice and a third, yet unchallenged, source-behaviorist scholarship-provides for a more nuanced understanding of how these various players attend to and borrow language from one another, and how the prevailing strategies of disability rights (better laws) and special education reform (improved practice) are inadequate in accounting for the way violence is actually mobilized through an always already shifted signification process. I explore some examples below.

The always shifting signification process is evident in the body of existing attempts to curtail the use of restraint and seclusion in schools. Definitions of what restraint is, what process is actually being described, and whether it is a physical, legal or discursive problem differ wildly, and no clear consensus has been established. Current scholarly interventions into R\&S policy come from the fields of legal studies, educational leadership and public policy and largely explore legal and procedural approaches to restricting $\mathrm{R} \& \mathrm{~S}$ in schools. The failure of reporting procedures and policies has been explored (Gagnon et al., 2017). Gagnon, Mattingly and Connolly reported that the majority of school districts reported no or very few instances of R\&S, with $69.2 \%$ of school districts reporting no cases of restraint, and $87 \%$ of districts reporting no cases of seclusion in 2012. Policy work from special education advocates has focused on the type of restraint used, time limits, and the training required to restrain (Simonsen et al., 2015, p. 436). Legal scholars have questioned the legitimacy of R\&S. Legal Scholar Justin Farrell's work on R\&S, for example, points to problems in the differentiation between parental rights and the rights of the child in IDEA, and proposes a legal framework to ensure children's rights in cases 
Roscigno, Semiotic Stalemate

CJDS 9.5 (December 2020)

involving adversities-court oversight and a legal process for approval of the use of adversaries outside of the IEP team (Farrell, 2004, p. 419). Educational Leadership scholarship on the topic is largely concerned with evidence-based practices, Positive Behavior Intervention and Supports, and training/professional development (Scheuermann et al., 2016). All of these diverse approaches operate with a remarkably different understanding of the phenomenon of R\&S, and evidence an unstable signifier.

One common theme throughout the U.S. state regulations is the allowance of restraint when a student is a harm to themselves or others, without an operational definition of "harm". For example, Illinois School Code Section 1.285 indicates restraint may only be used if the student "poses a physical risk to himself, herself or others" and that R\&S procedures "shall be used only as means of maintaining discipline in schools (that is, as means of maintaining a safe and orderly environment for learning) and only to the extent that they are necessary to preserve the safety of students and others" (Ill. Sch. Code $\S 1.285)$. Iowa Administrative Code indicates staff may use "reasonable force" to "quell a disturbance or prevent an act that threatens physical harm to any person," "prevent a student from the self-infliction of harm" or to "protect the safety of others" (Iowa Ad. Code $\S 281-103.4(256 B, 280)$. New Jersey’s recently passed N.J. 1163 authorizes the use of Restraint or Seclusion in case "emergency in which the student is exhibiting behavior that places the student or others in immediate physical danger.” (N.J. Gen. Stat. §1163). These definitions, while a small sample, do not define what constitutes physical danger that would warrant the use of R\&S. To contrast, Florida's Discipline Procedures for Students with Disabilities defines serious bodily injury to mean "bodily injury which involves a substantial risk of death; extreme physical pain; protracted and obvious disfigurement; or protracted loss or impairment of the function of bodily member, organ, or mental faculty" (Florida Ad.Code $§ 6 A-$ 
$6.03312(1)(d))$. The legal reality of restraint being justified by an ideological construct that is loosely defined, like "emergency" or "safety," applied by those in power, points to a recursive process between the ever-expanding list of behaviors termed pathological within behaviorist scholarship and the justification of restraint within the law. It is to be noted, that while the legal context given here is specific to U.S. case law, a similar logic exists in other nations that have made attempts to curb the use of restraint and seclusion. For example, Inclusion B.C, a Canadian disability rights organization, has released two separate white papers on the use of R\&S (Stop Hurting Kids, 2013; Stop Hurting Kids II. 2017). In the second document, the organization explicitly calls for "Prohibiting the use of restraint and seclusion in all BC schools, except where necessary to preserve the safety of the child and others (Stop Hurting Kids, 2017, p. 10). The recommendations still provide a provision for "harm", and considering the global export of ABA, it is likely the argumentation will still have the same rhetorical flaws.

For example, in the U.S., legal challenges to the use of R\&S have gone through several channels (Farrell, 2004). Many parents have challenged abuse of their children through the $14^{\text {th }}$ Amendment of the U.S. Constitution. In one such case, Domingo vs. Kowalski, a group of parents alleged that Marsha Kowalski, their children's teacher, abused their children by "among other things, gagging one student with a bandana to stop him from spitting, strapping another to a toilet to keep her from falling from the toilet, and forcing yet another to sit with her pants down on a training toilet in full view of her classmates to assist her with toilet-training" (Domingo v. Kowalski, 2014). The court upheld that Kowalski did not violate the children's Constitutional rights based on the "Gottlieb test," a litmus test from another case (Gottleib Calabria v. Laurel Highlands School District, 2001), to determine whether what occurred would "shock the conscious". The Gottleib test "first looks to the ends motivating the teacher's actions and not the 
means undertaken to achieve those ends". The criteria used to evaluate the degree of shock in Gottleib were as follows:

a) Was there a pedagogical justification for the use of force?; b) Was the force utilized excessive to meet the legitimate objective in this situation?; c) Was the force applied in a good faith effort to maintain or restore discipline or maliciously and sadistically for the very purpose of causing harm?; and d) Was there a serious injury? (Gottleib Calabria $v$. Laurel Highlands School District, 2001)

In other words, the nature of the abuse is secondary to the intent and pedagogical function and anything that is considered pedagogical in nature is not, according to the Gottlieb test, abuse. The teacher only must prove their intervention is pedagogical in nature to categorically separate it from abuse. This is one such failure of the law to negotiate the ways that the law upholds violence and the recursive relationship between behaviorism, schools and the law. If restraint and seclusion are established within the corpus of behaviorist scholarship as pedagogical in nature, it is very difficult to constrain practices like restraint or seclusion.

\section{Self-Restraint as Slippery Signifier}

There is a slippage between the law, teaching practice and the corpus of behaviorist literature. I will trace one term-self-restraint-to draw conclusions about the nature of the relationship between these three seemingly stable and discrete entities. I do so to argue that this relationship, and the fluidity with which concepts and rhetorical dodges are created and exploited through these relationships creates a moving target that is difficult to anticipate, and to resist through the same channels-namely law and teaching practice. I use self-restraint as a case study to demonstrate the instability of the relationship between the discourse of harm and the material 
Roscigno, Semiotic Stalemate

CJDS 9.5 (December 2020)

conditions of physical harm. I argue that this slippage is a core enabler of violence and primary reason that attempts to curb the use of restraint and seclusion have been unsuccessful.

One of the central tenets of behaviorism, and by extension Applied Behavioral Analysis is the focus on the observable. Within a behaviorist paradigm, observable behaviors are coded, categorized and analyzed. This requires definitions to be operationalized, or to be described in discrete units, which are categorically differentiated from other units or classes of behavior. Terminology was developed to describe these discrete units of observable behavior. Some examples of broad categories within behaviorist scholarship are Self-Injurious Behavior (SIB), Self-Stimulatory Behavior, Echolalic Behavior, Automatically Reinforcing Behavior, and so on. "Self-restraint" is one of the many categories of behavior within behaviorism. Self-restraint, as a cohesive category of behavior, first appears in the Behavior Analytic literature in 1968. Behavioral psychologists identified a new class of behaviors during their study of children who engaged in Self-Injurious Behavior (SIB). They described potential examples of self-restraint such as sitting on ones hands, wrapping them in clothing or other items, or seeking out otherwise restrictive apparati (Baroff \& Tate, 1968). By 1992, self-restraint is codified in the literature (Smith et al., 1992). Smith et al. state, “Typically observed topographies of self-restraint include entanglement of limbs in clothing, furniture or body parts" (Smith et al., 1992, p. 433). A systematic review of all studies in the Journal of Applied Behavioral Analysis involving “treatment" for self-restraint was conducted for this study. Treatment procedures for "selfrestraint" ranged from electro-shock to removal of clothing, physical restraint or seclusion. Interestingly, self-restraint almost always reduces SIB in individuals, yet, Smith, Iwata and others (1992) have argued that self-restraint is the same functional class as SIB. Subsequent studies have indicated that SIB has an inverse relationship to self-restraint, and yet, self-restraint 
is constructed as categorically pathological and in need of intervention and of evidence of a "compulsive" nature in Autistic children (Richards et al., 2017).

Behaviorism relies on a fundamental assumption: signifiers are stable, and the signsignifier relationship is linear. The term self-restraint, in this formation, reliably refers to a class of behaviors that is empirically true, visible and measurable. This is a Saussurian formationsignifier and what is signified. This is what most of the opposition to restraint and seclusion (as well as its defendants) believe is operating in this discourse. "Harm to oneself," for example, appears to be a universally understood concept where the term "harm" neatly describes the phenomenon at hand. However, Deleuze and Guattari argue that the space between the reader and their texts is a productive space - full of multiplicity —and that distortions occur between the reader's preconceived notions of the text. This results in expansive, multiplicious meanings.

In keeping with this, I propose that Guattari's suggested semiotic classifications provide a more complete representation of semiosis that is able to account for semiotic formations that serve the institution (Guattari, 1984, p. 73). Guattari also offers a means of resistance that goes beyond the lexicon of the signifier to open up the possibility of coalition through “deterritorialized material fluxes." (Guattari, 1984, p. 75). In Molecular Revolution: Psychiatry and Politics, Felix Guattari offers a configuration of semiotics that goes beyond signification. Guattari begins by asserting that his formation is an expansion of Hjelmselv and Saussure. Hjelmselv proposed four categories: substance, form, content and expression-similar to Saussure's signifier and signified. Guattari proposes an alterior formation-a-signifying semiotics. His categories are such (Guattari, 1984, pp. 74-75):

\section{Non-semiotic encodings}

\section{Signifying semiologies}




\section{A-signifying semiotics}

Non-semiotic encodings, according to Guattari, are encodings that are natural, and which function independently of the construction of semiotic substances. Nature, in this formation, is outside of a semiotic code, functioning without inscription. Signifying semiologies are based on "systems of signs, on substances formed semiotically and having a relationship of formalization on the plane of both content and expression" (Guattari, 1984, p. 74). This is what Guattari calls the "dictatorship of the signifier" and the establishment of state power. The signifier, here, is totalitarian. In the behaviorist tradition, the signifier is deployed to reterritorialize the autistic body. The schism of the materiality from the realm of signification is a strategic flattening that serves the interests of the behaviorist. Guattari states, "The signifying semiotic sustains the illusion that a level of "the signified" exists in order to delay, or interfere with, or even present a direct conjunction between sign machines and real machines (Guattari, 1984, p. 91). In other words, the signifying semiotic creates a mirage-a stable relationship between form, substance, content, and expression. In the case of self-restraint, the signifying semiotic helps the behaviorist posit that self-restraint is a concept that in fact maps onto an observable segment of human behavior, one that is timeless and universal. A stable category that is divorced from the material is necessary for the various social machines to function together. Guattari specifically references behaviorists and psychoanalysts in his explanation of signifying semiotics, stating "what is constant is the idea that one must discover a univocal reference point, a transcendent invariable, not itself significative, whereby to explain the sum of the significative arrangements." (Guattari, 1984, p. 89). In this case, the child cannot be restrained with impunity unless it is established that they are a harm to oneself. "Harm" here is constructed as a stable signifier that reliably points to a set of behaviors that bring empirical harm to the child. However, the definition of 
self-restraint forges a relationship between an array of neutral embodiments (like sitting on one's hands, wrapping one's hands in clothing, etc.) and a moniker of harm or "self-restraint". The definition of harm is thus widened to include most/all of the possible bodily assemblages of the disabled child, widening the application of restraint, seclusion, and other violent teaching procedures. If the processes of signification allow everything the child does to be harm, and everything the behaviorist does to be pedagogy, then within a law that allows for violence only to reduce harm or teach, then the capacity for that violence is limitless.

Guattari's contribution is the third register of signification-what he calls "a-signification." A-signification or post-signifying semiotics uses semiotics of signification as a tool, but accounts for a materiality outside of signification. He adds matter into the equation-positing that there may be a material flux outside of a closed semiotic substance, operating independently. Guattari's interest in a politics on a-signification as a means of thinking outside of the power of the analyst is to imbue the material with a significance and political power. His examples are particularly well-suited to a discussion of restraint as they deal with the disabled child. He first discusses "the psychotic child banging its head against the wall day after day". To Guattari, this action is not the individual pathos of the child, but an act of collective praxis. He states,

How could the desire energy on banging-one's-head-against-the-wall be related in any way to collective engagement? It is not a matter of transposing or sublimating this activity, but getting it to function on a semiotic register that be can be connected up to certain other non-signifying systems; not of curbing the desire or changing its objects, but of broadening the field of jouissance, opening up new possibilities. (Guattari, 1984, p. 80) Guattari reframes self-injurious behavior, a compelling justification for restraint and seclusion, as a political act, possessing a desire energy that has a political power. The second example is the 
child playing with its own shit. Guattari argues that signification "tries to transform this pleasure, this matter, into a semiotic substance that can be translated and interpreted according to the dominant code, it ends up mutilating it or destroying it." (Guattari, 1984, p. 80). It is the role of the institution to transform desire into something else, ushering in new technologies of control. The shit narrative, or the shit-smearing narrative is a common justification for the nonhumanness of the autistic child, as Melanie Yergeau points out. She discusses shit narratives in Authoring Autism (2017), stating "These are shitty narratives-rhetorical commonplaces that author autistic people as victim-captives of a faulty neurology, as rhetorically degraded and rhetorically suspect. In these constructions, our shit holds more rhetorical power than we do." What Guattari's a-signification does is account for the political potential of the a-semiotic, the organless body. Non-signifying collectives are a possibility of a-signification, deterritorialized, and thus non-individuated. The organless body is connected "to a multiplicity of desiring intensities" (Guattari, 1984, p. 98). Self-restraint is an act of desire-an a-semiotic material encounter. And while the term applied to it (restraint) is analogous with neoliberal notions of self-control and industriousness, the material encounter is less about restraint than it is about freedom. Applying the term "restraint" to these acts is an attempt at reterritorialization, however, the slippage between the attempt to control the body vis-à-vis behavioral classification and its corporal resistances allows for some fleeting liberation, even within an ultimately oppressive structure. The Guattarian understanding of semiotics accounts for the production of meaning that occurs between the material and the discursive.

The following section will detail how these processes map onto the established literature on self-restraint, and how the autistic body is what Deleuze and Guattari call a "body without organs" (Deleuze \& Guattari, 2009, p.9) or a collection of disorganized, unfettered entities. 
Roscigno, Semiotic Stalemate

CJDS 9.5 (December 2020)

Viewing the Autistic body politic as an organless body allows for the acts of those marginalized within discourses of Disability Rights and Neurodiversity activism (such as those confined within the four walls of an institution) to be valuable, important contributors. This crucial reframing opens up new lines of flight through desire and jouissance-providing a counter to calls for rights, recognition and inclusion within disability studies in education.

\section{Case Study: Adam}

This case study comes from an article in The Journal of Intellectual Disability Research titled, "Restraint Fading and the Development of Alternative Behavior in the Treatment of SelfRestraint and Self-Injury” (Guattari, 1984, p. 78). The study's subject, Adam, was a 20 year old man with Hirshprung's Disease. Adam was institutionalized at the age of 5. His self-injury was reported to be "ear rubbing, face, neck arm and shoulder scratching and head, ear, and chin hitting." His self-restraint consisted of "wrapping his arms in his shirt, holding objects between his head and shoulders, and putting his head and arms through openings in the furniture" (Lerman et al., 1994). At the time of the study, Adam's SIB was being "controlled" through “intermittent water misting" and wearing a football helmet, though he continued to "selfrestrain" by putting his hands in his shirt. Setting conditions were established through a series of experiments where Adam was permitted to self-restrain, or the "restraint" was unavailablemeaning Adam was stripped of his shirt. Data was collected on instances of SIB in either condition and SIB was near zero in the "restraint available" condition. An intervention was designed to decrease Adam's self-restraint. Adam's self-restraint was “transferred" to a towel and then a bandana and then a wristband, and throughout the experiment, he was physically blocked from his shirt, or not permitted to wear one, and reinforced with food for using the new items. 
Roscigno, Semiotic Stalemate

CJDS 9.5 (December 2020)

Adam's case demonstrates how "self-restraint" marked his body for abuse and humiliation. Adam's behaviors are first intervened in through the use of a football helmet and being sprayed in the face with water. At the beginning, Adam's body is already subject to routine violence. Then his "self-restraint," despite not being demonstrably harmful, becomes the subject of intervention. The intervention itself is humiliating-being prevented from wearing clothing, and also involves actual physical restraint-as Adam is "physically prevented" from SIB. What is relevant here is the circuitous path that violence takes from the disabled body to the therapist through a process of signification. Adam's own "violence" (despite being largely innocuous) is constructed as harm to himself, yet the "intervention" is demonstrably more violent and humiliating than the original behavior yet is rhetorically understood as pedagogical.

I want to propose three readings, based on Guattari's semiotic formations.

1. Non-Semiotic Encodings: The first of Guattari's distinctions removes substance from the chart, leaving only a form and content of expression. Perhaps this would render Adam's motions natural, emerging from a genetic code that in imperceptible or unable to be understood linguistically. The interpretive process would only focus on the naturalness of Adam's motions relative to an invisible genetic code.

2. Signifying Semiotics: The reading presented in the original text is entrenched in a politics of signifying semiotics. Adam's behavior of "ear rubbing, face, neck arm and shoulder scratching and head, ear, and chin hitting" can be reliably mapped onto the operational definition of selfrestraint, thus justifying the treatment of having his shirt, and subsequently his ability to selfrestrain, removed. This also justifies the use of restraint. Were this case to be litigated by Adam or his parents, the therapists would most likely pass the Gottleib test and be able to claim that the restraint served a pedagogical function. In a school setting, and under most states' restraint and 
seclusion law, Adam would also be classified as a harm to himself and/or others. For activists and scholars operating within this paradigm, the problem of restraint would most likely be to pass stricter laws with more reporting, or perhaps to provide better training for teachers and therapists in crisis management and positive behavior supports. Likely, Adam's rights, educational and human, would be invoked to try to limit the punitive aspects of his treatment. Perhaps, a change in placement would be called for, or IDEA leveraged to make claims about Adam's ability to access FAPE. However, the semiotic configurations of the terms of analysis would not be interrogated. Behaviorists claim Adam has a right to evidence-based treatment, while opponents claim he has a right to inclusion, bodily autonomy, etc. Adam's own material resistance lurks under the edifice of more official forms of resistance-through legal channels, the IEP process, etc. Adam also is understood as a singularity-one person amidst a system that services individuals.

3. A-Semiotic Signification: Guattari's contribution to the Hjelmslev's schematic enables a rereading of this archive. Here I take on what Guattari calls a "schizoanalysis"; seeking to: foster a semiotic poly-centrism by assisting the formation of relatively autonomous and non-translatable semiotic substances, by giving equal acceptance to all desire whether it makes sense or not, by not seeking to make subjectiviation fit in with the dominant significations and social laws. Far from its objective being to 'cure' people of behaviour that falls outside of the usual norms, it finds a place for all the singularities of those who, for one reason or another, are an exception to the general rule. (Guattari, 1984, p. 78) Guattari conceives of a material force that counters the "analytic rush" of the clinic-one that is a collective resistance formed by an embodied resistance to the hierarchies of familial relations, labor relations, etc. Re-reading Adam's story through this lens, Adam can be understood as a- 
semiotic; moving between signifiers and the impetus to lay epistemological claim to his embodiments. His desire for pleasure, for the release of tension through his "self-restraint" or self-pleasure becomes the mechanism of his resistance. This is a struggle waged within the walls of the institution, through a "micro-politics of desire". The desiring body, even under the confines of the institution, is capable of a different type of intervention. For Guattari, this is a collective power. The system of signification is based on individuation and identification, thus the way out is to reject the "will to identity" in favor of an "organless body that deindividuates desire" (Guattari, 1984, p. 80). Perhaps autistic embodiment is a particularly strong desiring machine-seeking pleasure in new and creative ways. Thinking outside of an individual-rightsbased framework opens up the political possibility of desiring, organless, autistic and neurodivergent bodies who do the work of liberation collectively. Perhaps also, this explains why such elaborate technologies of control have been so specifically designed for these bodies in particular.

\section{Conclusion: Life Beyond a Semiotic Stalemate}

This project is an attempt to theorize why existing attempts at prohibiting restraint and seclusion have proven to be a particularly difficult task. It is no longer plausible that training, lack of laws, lack of services, staff or understanding of disabled people are the cause of the sustained use of these practices. One important and overlooked variable is the production of terms-signifiers-within behaviorist scholarship and the conduit between the discipline of $\mathrm{ABA}$ and classroom policy and practice. The large-scale adoption of behaviorism in public schooling has been explored peripherally (Kohn, 2018), but the tangible effects of the meteoric rise in Board Certified Behavior Analysts in the classroom is yet unexamined in Critical Disability 
Roscigno, Semiotic Stalemate

CJDS 9.5 (December 2020)

Studies. I argue behaviorism's focus on operationalizing and defining terms lends an air of impenetrability that has deterred scholars from interrogating the validity and stability of these categorizations-categories that have been adopted in special education classrooms writ large. The idea that all human behavior can be categorized into discrete functions is accepted as objective Truth and has infiltrated the IEP process and federal special education law. The language of behaviorism has become inseparable from the language of special education. Within the field of ABA, care has been taken to define terms in ways that expand the power and position of the BCBA in the classroom. The child now has a "right" to "effective treatment" which in this paradigm means only ABA, only interfacing with a BCBA, using only behaviorist methodology which includes the use of restraint, seclusion and punishment as "teaching procedures."

It is not surprising then, that campaigns for better $R \& S$ laws have done little to reduce their use. A claim to human rights becomes ineffective when the academic discipline influencing the law defines harm as NOT being restrained. If we (activists) continue to operate with the assumption that these signifiers are stable and universal, nothing will improve. The case study of the term "self-restraint" demonstrates how quickly "harm to oneself" can shift and evolvemarking some bodies as always harmful, always in need of correction. In one breath, the child's body is made harmful and any action taken against the child is thus well within existing laws that allow violence to "prevent harm". It matters not if that "harm" is not empirically harmful. The use of punishment as a teaching procedure within a legal system that only requires harm to be "pedagogical in nature" to be excused is a dangerous recursive that needs to be demystified. I offer Guattari's model of signification as a way to demystify this process and to think through resistance, desire, and strategy. What is so fruitful here is that in this formulation, resistance comes from the body, not in spite of it. We can look to the archive and find instances of the type 
Roscigno, Semiotic Stalemate

CJDS 9.5 (December 2020)

of unfettered desire and organless bodies that engage in direct-action-at-all-costs; the types of bodies that free us from a semiotic stalemate of rights and recognition through pleasure. This is an embodied, a-signifying semiotics where the materiality of shit, the head-banging autistic, the masturbating child are leaders of a collective resistance. 
Roscigno, Semiotic Stalemate

CJDS 9.5 (December 2020)

\section{References}

Abstracts of the Conference on the Experimental Analysis of Behavior. (1959). Journal of the Experimental Analysis of Behavior, 2(3), 249-269. https://doi.org/10.1901/jeab.1959.2249

Baroff, G. S., \& Tate, B. G. (1968). The use of aversive stimulation in the treatment of chronic self-injurious behavior. Journal of the American Academy of Child Psychiatry, 7(3), 454470. https://doi.org/10.1097/00004583-196807000-00005

Behavior Analyst Certification Board. (n.d.). BACB certificant data. https://www.bacb.com/bacb-certificant-data/

Bijou, S. W. (1958). Operant extinction after fixed-interval reinforcement with young children. Journal of the Experimental Analysis of Behavior, 1(1), 25-29. https://doi.org/10.1901/jeab.1958.1-25

Bijou, S. W., Dougher, M., Redd, W. H., Porterfield, A. L., \& Barbara, L. (2009). In memoriam. The Behavior Analyst, 2(2), 363-364.

Bostow, D. E., \& Bailey, J. B. (1969). Modification of severe disruptive and aggressive behavior using brief timeout and reinforcement procedures. Journal of Applied Behavior Analysis, 2(1), 31-37. https://doi.org/10.1901/jaba.1969.2-31

Burning Glass Technologies. (2015). Understanding the national demand for behavior analysts (pp. 1-15). Behavior Analyst Certification Board. http://www.bls.gov/soc/

Crystal Bonvillian, C. M. G. N. C. D. (n.d.). School where 13-year-old with autism died after being restrained violated state rules. Myajc. https://www.myajc.com/news/crime-law/school-where-year-old-with-autism-died-after-being-restrained-violated-staterules/LwLGvVY15YJ77MRWcyspJN/ 
Roscigno, Semiotic Stalemate

CJDS 9.5 (December 2020)

Deochand, N., \& Fuqua, R. W. (2016). BACB certification trends: State of the states (1999 to 2014). Behavior Analysis in Practice, 9(3), 243-52. https://doi.org/10.1007/s40617-0160118-Z

Domingo v. Kowalski, Case No. 3:13 CV 94 (United States District Court for the Northern District of Ohio Western Division August 29, 2014). https://casetext.com/case/domingov-kowalski

Escalante, E. (n.d.). 13-year-old student dies after being restrained at school. WFMY. https://www.wfmynews2.com/article/news/nation-world/13-year-old-student-dies-afterbeing-restrained-at-school/83-623246934

Farrell, J. J. (2004). Notes protecting the legal interests of children when shocking, restraining, and secluding are the means to an educational end. St. Johns Law Review, 83, 395-427.

Ferdinand, D. (1966). Course in general linguistics. McGraw-Hill.

Foringer Co. (1959). Teaching machines in experimental models [Print Advertisement]. Journal for the Experimental Analysis of Behavior, 2(2), n.p.

Gagnon, D. J., Mattingly, M. J., \& Connelly, V. J. (2017). The restraint and seclusion of students with a disability: Examining trends in U.S. School districts and their policy implications. Journal of Disability Policy Studies, 28(2), 66-76.

https://doi.org/10.1177/1044207317710697

Giacomo Luca. (2019, January 25). Guiding Hands School: How a student's death led to its closure after 25 years | abc10.com. ABC10. https://www.abc10.com/article/news/guidinghands-school-how-a-students-death-led-to-its-closure-after-25-years/103-581e1598-56a4420e-8128-42894ce6c70d 
Roscigno, Semiotic Stalemate

CJDS 9.5 (December 2020)

Gottleib Calabria v. Laurel Highlands School District, No. 00-3422. (United States Court of Appeals, Third Circuit. November 15, 2001). https://caselaw.findlaw.com/us-3rdcircuit/1333448.html

Guattari, F. (1984). Molecular revolution: Psychiatry and politics. Penguin Group USA.

Hall, R. V., Lund, D., \& Jackson, D. (1968). Effects of teacher attention on study behavior. Journal of Applied Behavior Analysis, 1(1), 1-12. https://doi.org/10.1901/jaba.1968.1-1

Harkin, T. (2014). Dangerous use of seclusion and restraints in schools remains widespread and difficult to remedy: A review of ten cases Majority Committee Staff Report. https://www.help.senate.gov/imo/media/doc/Seclusion\%20and\%20Restraints\%20Final\% 20Report.pdf

Hart, B. M., Reynolds, N. J., Baer, D. M., Brawley, E. R., \& Harris, F. R. (1968). Effect of contingent and non-contingent social reinforcement on the cooperative play of a preschool child. Journal of Applied Behavior Analysis, 1(1), 73-76. https://doi.org/10.1901/jaba.1968.1-73

Individuals with Disabilities Education Act (IDEA), 34 CFR $§ 300.530$ Code of Federal Regulations (2004). https://www.law.cornell.edu/cfr/text/34/300.530

Keller, F. S. (1968). “Good-bye, teacher ...”. Journal of Applied Behavior Analysis, 1(1), 79-89. https://doi.org/10.1901/jaba.1968.1-79

Kohn. (n.d.). Punished by Rewards. https://www.libraries.rutgers.edu/rul/eresa/reserve_aa/phtml/ServeRes.php?file=\%2Fu4\% 2Frul\%2Feres\%2Ffal17\%2Fsargentt_05_300_200_01_kohn_lures.pdf

Kutz, G. D. (2009). Seclusion and Restraints: Selected Cases of Death and Abuse at Public and Private Schools and Treatment Centers. https://www.gao.gov/new.items/d09719t.pdf 
LERMAN, D. C., IWATA, B. A., SMITH, R. G., \& VOLLMER, T. R. (1994). Restraint fading and the development of alternative behaviour in the treatment of self-restraint and selfinjury. Journal of Intellectual Disability Research, 38(2), 135-148. https://doi.org/10.1111/j.1365-2788.1994.tb00369.x

Maglione, M., Kadiyala, S., Kress, A., Hastings, J. L., \& O’Hanlon, C. E. (2017). TRICARE Applied Behavior Analysis (ABA) Benefit. Rand Health Quarterly, 6(2). https://www.ncbi.nlm.nih.gov/pmc/articles/PMC5568164/

Keeping All Students Safe Act, H.R. 4247 (2010) (testimony of Rep. George Miller).

O’ Brien, F., Azrin, N. H., \& Bugle, C. (1972). Training profoundly retarded children to stop crawling. Journal of Applied Behavior Analysis, 5(2), 131-137. https://doi.org/10.1901/jaba.1972.5-131

Özerk, K., Dalby Vea, G., Eikeseth, S., \& Özerk, M. (2016). Ole Ivar Lovaas-his life, merits and legacy. International Electronic Journal of Elementary Education.

Philip Reesby Sawson Morror and. (2018, December 7). School where student with autism collapsed and later died violated restraint rules, California regulators find. The Sacramento Bee. https://www.sacbee.com/latest-news/article222799470.html

Richards, C., Davies, L., \& Oliver, C. (2017). Predictors of self-injurious behavior and selfrestraint in autism spectrum disorder: Towards a hypothesis of impaired behavioral control. Journal of Autism and Developmental Disorders, 47(3), 701-713. https://doi.org/10.1007/s10803-016-3000-5

Risley, T. R. (1968). The effects and side effects of punishing the autistic behaviors of a deviant child. Journal of Applied Behavior Analysis, 1(1), 21-34. https://doi.org/10.1901/jaba.1968.1-21 
de Saussure, F. (1966). Course in General Linguistics. McGraw-Hill.

Scheuermann, B., Peterson, R., Ryan, J. B., \& Billingsley, G. (2016). Professional practice and ethical issues related to physical restraint and seclusion in schools. Journal of Disability Policy Studies, 27(2), 86-95. https://doi.org/10.1177/1044207315604366

Shook, G., \& Favell, J. (2008). The Behavior Analyst Certification Board and the Profession of Behavior Analysis. Behavior Analysis in Practice, 1(1), 44-48. https://doi.org/10.1007/BF03391720

Shook, G. L. (2005). An examination of the integrity and future of the Behavior Analyst Certification Board[R] Credentials. Behavior Modification, 29(3), 562-574. https://doi.org/10.1177/0145445504274203

Shook, G. L., \& Neisworth, J. T. (2005). Ensuring appropriate qualifications for Applied Behavior Analyst professionals: The Behavior Analyst Certification Board. Exceptionality, 13(1), 3-10. https://doi.org/10.1207/s15327035ex1301_2

Simonsen, B., Sugai, G., Freeman, J., Kern, L., \& Hampton, J. (2015). Ethical and professional guidelines for use of crisis procedures. Education and Treatment of Children, 37(2), 307322. https://doi.org/10.1353/etc.2014.0019

Smith, R. G., Iwata, B. a, Vollmer, T. R., \& Pace, G. M. (1992). On the relationship between self-injurious behavior and self-restraint. Journal of Applied Behavior Analysis, 25(2), 433-445. https://doi.org/10.1901/jaba.1992.25-433

Thomas, D. R., Becker, W. C., \& Armstrong, M. (1968). Production and elimination of disruptive classroom behavior by systematically varying teacher's behavior. Journal of Applied Behavior Analysis, 1(1), 35-45. https://doi.org/10.1901/jaba.1968.1-35 
Roscigno, Semiotic Stalemate

CJDS 9.5 (December 2020)

Vollmer, T. R., Hagopian, L. P., Bailey, J. S., Dorsey, M. F., Hanley, G. P., Lennox, D., Riordan, M. M., \& Spreat, S. (2011). The association for behavior analysis international position statement on restraint and seclusion. The Behavior Analyst, 34(1), 103-10.

Zeilberger, J., Sampen, S. E., \& Sloane, H. N. (1968). Modification of a child's problem behaviors in the home with the mother as therapist. Journal of Applied Behavior Analysis, 1(1), 47-53. https://doi.org/10.1901/jaba.1968.1-47 